\title{
A pessoa e o ofício de Paulo Freire
}

HADDAD, Sergio.

O educador: um perfil de Paulo Freire.

São Paulo: Todavia, 2019. 256 p.

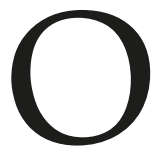

professor, pesquisador e ativista social Sergio Haddad é um dos mais importantes estudiosos e críticos das obras de Paulo Freire, no Brasil. Possui formação acadêmica interdisciplinar (graduação em economia e pedagogia, mestrado e doutorado em história e sociologia da educação) - conhecimento acadêmico que, somado à atuação em comissões e conselhos nacionais importantes para os caminhos da educação brasileira (Comissão Nacional de Alfabetização e Educação de Jovens e Adultos; Conselho Técnico-Científico da Educação Básica da Capes; Conselho de Desenvolvimento Econômico e Social da Presidência da República, dentre outros conselhos de entidades da sociedade civil), forneceu a Haddad condições para reflexões consistentes, críticas e oportunas sobre as contribuições freirianas nos campos educacional, social e político.

Um mosaico construído a partir do criterioso conglomerado de fatos da vida pessoal e profissional de Paulo Freire, justaposto às produções acadêmicas desse pensador, resultou no livro O educador: um perfil de Paulo Freire, título que explicita com excelência o que o leitor encontrará no texto. Nessa literatura biográfica, Sergio Haddad busca de um lado resgatar o compromisso de vida com a educação de um dos mais célebres intelectuais do século XX; e, de outro, recompor o complexo e extraordinário caminho trilhado por Freire, disponibilizando aos leitores a oportunidade de conhecê-lo e compreender o mérito do honroso título de patrono da educação brasileira, recebido em 2012.

Haddad apresenta narrações e descrições minuciosas da trajetória pessoal e profissional desse educador, sobretudo aquelas ocorridas no período de exílio. Para tanto, organiza a obra em uma apresentação e treze capítulos.

Na parte introdutória, menciona a preocupação com algumas condições de produção, uma vez ter objetivado a elaboração de um texto com linguagem simples, destinada ao público não leitor de Freire, em que o conteúdo abordado também servisse de esclarecimento sobre a pessoa e o "ofício" de Paulo. Isso porque, segundo o autor, há uma propagação de inverdades sobre o educador - usadas inclusive como argumentos daqueles que reconhecem ou não os construtos freirianos. Por isso, faz-se necessário fundamentar os debates para além do campo da educação (HADDAD, 2019:9).

No capítulo 1, o relato de um dos momentos mais tenso da biografia de Paulo Freire: a perseguição política no período do Golpe Militar de 1964. Posteriormente, o 
entrelaçamento da história pessoal com a profissional alinhavado por sua paixão pela educação. O clima de tensão produzido no primeiro capítulo é suavizado nos próximos cinco, em que se expõe a fase da infância, da vida matrimonial, das primeiras experiências profissionais e do desenvolvimento e aplicação do método de alfabetização de Paulo Freire. Nos quatro capítulos subsequentes, relatos das vivências do educador em diversas partes do mundo, como no Chile, nos USA, em Genebra e na África do Sul, durante o período de exílio. Os últimos capítulos, por sua vez, abordam o retorno de Paulo Freire ao Brasil, discorrendo sobre o processo de adaptação, sua atuação como secretário Municipal de Educação em São Paulo, seu falecimento e as críticas póstumas recebidas na conjuntura atual.

O primeiro capítulo, nomeado Um criptocomunista encapuçado sob a forma de alfabetizador, atua como gancho para os acontecimentos narrados no decorrer da obra. Haddad parte dos acontecimentos de $1^{0}$ de abril, conhecido historicamente como Golpe Militar de 1964, e situa Paulo Freire, que percebeu a inviabilidade de lançar 60.870 Círculos de Cultura para alfabetizar 8 (oito) milhões de cidadãos brasileiros (aproximadamente 8,9\% da população de 15 a 45 anos) naquele momento. $\mathrm{O}$ autor, por um lado, evidencia a percepção analítica do educador diante daquele contexto político, disponibilizando manchetes dos noticiários sobre o golpe; e, por outro, revela a preocupação de Freire também com a segurança de sua família. Esboça-se, de certo modo, o perfil do biografado ao apresentar pensamentos, sentimentos, fatos, datas e nomes de autoridades políticas. Pode-se dizer que é um capítulo denso, marcado pela descrição minuciosa do contexto político-educacional e do desconforto causado pela proposta freiriana de alfabetização das massas.

De acordo com Haddad, o Programa Nacional de Alfabetização era uma possibilidade real de milhares de brasileiros exercerem o voto, mas isso contrariava os interesses de uma elite. Representava uma ameaça aos "redutos políticos cativos nas eleições seguintes" (HADDAD, 2019:15) e, portanto, como foi publicado no artigo do médico e professor universitário Antônio Bernardes de Oliveira, em 30 de julho de 1964, no Jornal O Estado de S. Paulo, "o voto do analfabeto era um desserviço à Nação". O método de Paulo Freire, então, não passaria de "uma manobra para alcançar dos escopos, uma intensiva propaganda comunista e a eclosão de invencível força eleitoral de índole facciosa onde a demagogia teria as portas abertas" (HADDAD, 2019:16).

No final deste capítulo, o autor narra a mudança de Paulo Freire e a família para o Recife (PE), período que marcará sua história profissional. Ao aceitar trabalhar no Serviço de Extensão Cultural (SEC) da Universidade Federal de Recife, ele inicia atividades de alfabetização no Rio Grande do Norte. Em decorrência do sucesso, foi convidado para aplicá-las em todo o território nacional, oportunidade que o faz retornar a Brasília (DF).

No segundo capítulo, titulado Elza Maia Costa de Oliveira, o leitor terá acesso a narrativas da fase de vida Paulo Freire: do período da infância à adolescência, o início da vida profissional e o casamento com Elza. Sobre a infância, relatos do cotidiano familiar 
antes e após o declínio financeiro decorrente da queda da Bolsa de Nova York. Haddad apresenta detalhes das brincadeiras, dos primeiros romances, das experiências de Freire como aluno bolsista, do aprendizado e do gosto pela língua portuguesa. Na sequência, informações sobre o "descobrir-se professor", a formação na faculdade de Direito e o casamento com a educadora Elza.

O terceiro capítulo, A dureza da vida não deixa muito para escolher, contempla a trajetória profissional de Freire, evidenciando transformações nas concepções sobre o ensinar. A atuação no Serviço Social da Indústria (Sesi), no setor de Educação e Cultura, durante dez anos em que manteve relação interpessoal com os operários, gera um repensar sobre como mediar conhecimentos. Ao escutar os trabalhadores quanto às práticas adotadas na educação dos filhos, Paulo percebeu que os castigos físicos eram fruto das poucas condições emocionais e financeiras que tiveram. Modificou, então, o modo como interagia com aquele grupo, entendendo que "o processo educativo deveria partir da necessidade, da experiência, da realidade e da interpretação que os trabalhadores faziam dela" (HADDAD, 2019:42). Essas reflexões tornaram-se o embrião para a delimitação das linhas gerais do pensamento que o acompanharia ao longo da vida. Além do serviço no Sesi, a atuação na Igreja também contribuiu para formação do pensamento de Freire, acrescentando a defesa da participação democrática e do compromisso social e político; a formação por meio da participação familiar; a consideração pela realidade do aluno no processo educativo; a resistência à política assistencialista e o pensamento crítico da realidade.

Seguindo esse viés, no capítulo Uma enorme lata de Nescau descreve-se o processo de elaboração do método de alfabetização de Paulo Freire, motivado, a princípio, por uma vivência familiar. Ao perceber que o filho pareceu ler a palavra Nescau em um anúncio publicitário, mesmo sem conhecimento formal e sistematizado de língua que o permitisse à prática da leitura, Paulo buscou compreender o fato e elaborou as bases para seu método. Refletiu sobre como as imagens se conectam com as palavras e, consequentemente, como incorporaria a experiência do aluno no processo de aprendizagem da leitura e da escrita. Para isso, "produziu imagens sobre os assuntos; depois, definiu as palavras que seriam colocadas junto das imagens [...]. Por exemplo, ao pensar em um tema relativo às condições [...] de pedreiros, definiu que usaria a projeção da imagem de um tijolo, embaixo a palavra tijolo escrita" (HADDAD, 2019:59). Além disso, empregaria perguntas orientadoras para conduzir os alunos na formação de palavras geradoras. Esse método de leitura foi aplicado por Paulo, Elza e uma sobrinha em uma escola de Recife (PE). Depois, foi expandido por meio de parceiras como a estabelecida com a Prefeitura de Natal (RN) e com a juventude católica da Paraíba.

A popularização, o sucesso e as consequências do desenvolvimento desse método de alfabetização foram descritos nos três capítulos subsequentes. Em Hoje já não somos massa, estamos sendo povo detalha-se a primeira grande ação de alfabetização liberada por Paulo Freire em Angicos (RN), com apoio de governadores e lideranças políticas nacionais. Essa 
ação era importante para o País, que vivenciava um clima de popularização, de instabilidade política, de diversificação de posicionamento das forças de esquerda, de insatisfação popular, de inflação, de péssimas condições de trabalho geradas pela crise do Governo Jânio Quadros, dentre outros fatores (HADDAD, 2019:62).

Nesse cenário de mobilização social, o Programa Nacional de Alfabetização (PNA) liderado por Paulo Freire tornou-se um marco importante. A equipe de educadores se instalou na cidade potiguar para vivenciar a realidade do alunado, ao mesmo tempo em que aplicava o curso. Angico (RN) era uma típica cidade do sertão nordestino: com muitas carências, o trabalho na roça era o que garantia a subsistência da população. O Programa, por exemplo, na aula de encerramento dessa ação de alfabetização, contou com o apoio do presidente da República, de todos os governadores dos estados, além de outras autoridades (HADDAD, 2019:72). No entanto, devido ao impacto que essa ação poderia trazer aos resultados das eleições e por também discutir a consciência crítica partidária, o PNA, logo após o Golpe de 1964, foi extinto e Freire considerado uma ameaça (HADDAD, 2019:75).

Nos próximos capítulos, a descrição do martírio do educador nos primeiros anos de exílio, a relação com a família, o apoio dos amigos e as experiências profissionais que amadureceram o método de Freire. Em Viva o oxigênio, Haddad refaz o itinerário do biografado. Relata a partida de Paulo para Bolívia, destacando sentimentos, pensamentos e preocupações do exilado com a saúde física, pois não estava acostumado com a altitude, comenta sobre a breve estadia em La Paz e o contato do educador com os índios. Paulo, devido à tomada do poder pelos militares, migra para o Chile, etapa importante, pois lá, com a colaboração de Elza, começa a trabalhar no Instituto do Desarrolo Agropecuario (Indap) em Santiago, e a atuar diretamente na organização sindical camponesa. A partir daí, desenvolveu ações educativas com jovens e adultos do campo, buscando sempre uma emersão na realidade local para compreender as necessidades daquela comunidade.

Em Ninguém educa ninguém, por seu turno, tematiza-se a produção intelectual de Paulo Freire, incluindo a continuidade da produção da tese de doutorado. No exílio, com emprego estável, o educador pôde se dedicar ao trabalho intelectual, dando continuidade à sua filosofia educacional e ao aprimoramento do seu método de alfabetização. Nessa fase, escreveu, por exemplo, a obra Educação como Prática da Liberdade, com base na experiência em Angico ( $R N)$. Nela, foram apresentados os pilares do sistema freiriano: a não neutralidade da educação; a necessidade de educar em favor dos mais pobres; o diálogo como método de educar e a conscientização de educadores sobre os problemas sociais (HADDAD, 2019, p. 91).

Ainda no Chile, Paulo implantou seu método de alfabetização, via Organização das Nações Unidas para a Educação, a Ciência e a Cultura (Unesco), quando atuava como assessor no Instituto de Capacitação e Investigação em Reforma Agrária (Incira). Dessa vivência, resulta a produção da obra Pedagogia do Oprimido. Com o término do contrato nesse país, o educador passa uma temporada nos Estados Unidos da América, na 
Universidade de Harvad. Freire aproveitou para ampliar a dimensão política da educação, buscando compreender a periferia do país norte-americano, sobretudo quanto às temáticas racismo e xenofobismo. Depois disso, prestou serviço na Suíça, no Conselho das Igrejas Cristãs, situado em Genebra, promovendo formações pelo mundo com suas palestras. O princípio de que "ninguém educa ninguém. As pessoas educam em comunhão" surge neste contexto (HADDAD, 2019:101).

Uma caixa de Sonho de Valsas é o título atribuído ao oitavo capítulo, que trata do período de residência de Paulo Freire em Genebra, na década de 1970, ao ser contratado pelo Conselho Mundial das Igrejas (CMI) para trabalhar no departamento de educação. Dessa experiência, produz a obra O papel da igreja na América Latina, defendendo a teoria da libertação e a "fé nos oprimidos como motor da mudança social" (HADDAD, 2019:107). Durante os dez anos em que se vinculou ao CMI, dedicou-se a temática "libertação dos mais pobres" e divulgou suas contribuições por meio de palestras, cursos, conferências e mesa-redonda pelo mundo a fora. Na ocasião, aproveitando a experiência no Chile, publicou a coletânea Ação da Cultura para libertação, na versão inglesa, em 1979. A visibilidade de Paulo Freire no campo da educação já era notória e indiscutível. Solicitações para participação em eventos, por exemplo, nos USA, no Canadá e na Europa eram constantes. Outra empreitada importante realizada por Paulo, ainda na Suíça, consiste na criação do Instituto de Ação a Cultura (Idac), em que coparticiparam Elza e alguns amigos, também exilados. Dos resultados positivos das ações implementadas pelo Idac, decorreu o convite para o trabalho de alfabetização na África, inicialmente em Guiné-Bissau, país recém-libertado de Portugal.

Para descrever a contribuição da família Freire e dos membros do Idac nos países africanos, Haddad destina o nono capítulo intitulado por África: o limite da utopia. Segundo o autor, fora um grande desafio para Paulo Freire, pois a aplicação do método de alfabetização deveria considerar a heterogeneidade linguística, religiosa e cultural dos países africanos somada à variação de políticas linguísticas e dos currículos nas escolas. Em Guiné-Bissau, o crioulo era o mais falado pela população - apenas uma minoria usava o português, a língua do colonizador - e mais da metade da população era analfabeta. Para situar o leitor, Haddad comenta sobre o funcionamento dos três sistemas de ensino presentes neste país: um é destinado a uma minoria urbana com ensino herdado nos moldes de Portugal; outro, para combater o sistema português, ofertado em escolas construídas em barracões com objetivo revolucionário; e o terceiro, um sistema independente, baseado na troca de saberes das crianças, jovens e idosos.

Paulo e Elza buscaram conhecer os diferentes sistemas de ensino, pois para ela "o indivíduo vale enquanto gente. A pessoa humana é algo concreto e não uma abstração" (HADDAD, 2019:125). Eles entendiam a necessidade de se fazer um trabalho de reconstrução e alfabetização. No entanto, o português não era a língua oficial, o crioulo não tinha grafia estabelecida e o ensino não considerava a cultura africana em seu próprio 
currículo escolar. Mesmo assim, o serviço foi se expandindo a outros países: Cabo Verde, São Tomé e Príncipe e Angola. Segundo a prática educativa de Paulo, o ofício de ensinar demandava uma consciência política, por isso não fazia sentido alfabetizar aquela nação na língua que não fosse a dela. Esses impasses, especialmente as políticas linguísticas e educacionais, interferiram na concretização do projeto de alfabetização na África.

Os últimos capítulos: As universidades deveriam correr para contratá-lo; Reaprender o país; Nós acreditamos na liberdade e Minhas reuniões com Marx nunca me sugeriram que parasse de ter reuniões com Cristo, abordam o retorno de Paulo Freire ao Brasil, em 1979, no início do processo de abertura política.

Em As universidades deveriam correr para contratá-lo, Haddad recupera a manifestação de brasileiros pelo retorno dos exilados e a solicitação de uma participação mais democrática. Para tanto, relata um episódio da vinda de Paulo Freire ao Brasil para proferir uma palestra na Universidade Católica (PUC), em São Paulo. Como intelectual reconhecido, sua chegada provocou euforia entre populares, professores, alunos, autoridades e lideranças políticas que o receberam. Para Fernando Henrique "uma pessoa como Paulo não deveria deixar o País, as universidades deveriam correr para contratá-lo" (HADDAD, 2019:139). Com a anistia, o educador, após a primeira viagem, voltou ao Brasil para fixar residência e lecionar na PUC.

Em Reaprender o país, o autor retoma algumas críticas direcionadas a Paulo Freire, como a da comunidade acadêmica quanto à não filiação à ortodoxia marxista. No entanto, segundo o autor, para o educador era possível ler muitos autores e não necessariamente privilegiar um pensamento específico. Ele tinha preferência aos temas de suas matrizes principais como: 1. o cristianismo progressista, como se constata em Teoria da Libertação e na Pedagogia do Oprimido a partir do marxismo visto no Chile, e com 2. o colonialismo vivenciado na África (HADDAD, 2019:147). Esses conhecimentos ajudavam Paulo a formar seu pensamento crítico e ampliar as discussões sobre alfabetização, conduzindo os estudos freirianos ao diálogo com a linha do construtivismo e da perspectiva histórico-cultural, conforme apontado pelo autor. Freire, portanto, desejava que seu pensamento fosse avaliado pelo percurso de seus estudos e não por um recorte temporal das suas reflexões intelectuais. No final deste capítulo, além da descrição sobre a carreira frenética com homenagens e reconhecimento nacional e internacional, o autor comenta sobre a tristeza de Paulo ao perder sua grande companheira, Elza. Apresenta uma sequência de fotos ao lado de amigos e familiares, além de narrar a não aceitação dos filhos sobre o casamento de Paulo com Nita, sua segunda esposa.

Em Nós acreditamos na liberdade, a atuação política do educador no Brasil. Ele assume o cargo de secretário Municipal de Educação do Estado de São Paulo com a vitória para prefeita de Luiza Erundina, filiada ao Partido dos Trabalhadores (PT). O povo vivenciava um momento de muita expectativa com a chegada da esquerda ao poder. Paulo ajudou a formar o PT. Acreditava ser de sua responsabilidade a contribuição na primeira 
gestão. Em sua atuação como secretário, defendia: a "descentralização e a autonomia de cada unidade escolar" (HADDAD, 2019:197) e não apologia ao erro por partes dos educadores, pois para ele "não é possível entender a linguagem das pessoas sem o corte de classes sociais [...] há um tipo de comportamento para cada classe social [...]" (HADDAD, 2019:198). Enfim, uma gestão voltada para a humanização. No entanto, a equipe sofreu muita resistência para implementar as mudanças necessárias para uma educação como prática da liberdade. Isto abalou Paulo a ponto de querer deixar o cargo. Na primeira manifestação de sua decisão foi convencido a permanecer, mas tempos depois compreendeu ser a melhor decisão.

Por fim, no último capítulo da obra, retomam-se os anos finais vivenciados por Paulo Freire bem como o reconhecimento de suas contribuições para a educação e as críticas infundadas, na atualidade, sobretudo aquelas advindas do vigente Governo Federal.

Haddad, primeiramente, faz apontamentos sobre as viagens de Paulo com Nita e o prestígio intelectual que Freire continuou a receber até a morte, causada por insuficiência cardíaca em 2 de maio de 1997, além dos relatos de comoção no Brasil e no exterior por tal falecimento. Enumera, para fins de exemplificação, várias formas de reconhecimento da importância do construto freiriano: o recebimento, em vida, de 34 títulos de doutor honoris causas e mais cinco in memoria, somados aos incontáveis prêmios, títulos, estátuas, nomes de escolas, bibliotecas, ruas e tantas outras formas de legitimar seu ofício como educador. Feito isso, traz à tona questões políticas do período atual: da chegada à saída truculenta do Partido dos Trabalhadores da Presidência da República às críticas não só às obras como à pessoa de Paulo Freire, por uma onda conservadora que tomou conta do País.

Paulo foi militante político-partidário no PT e almejava que Luiz Inácio Lula da Silva chegasse à Presidência da República, mas não teve tempo para vivenciar os três mandatos do PT nem recuperar seu projeto de alfabetização interrompido pela ditatura. Em 2012, Paulo Freire recebeu o título de patrono da educação brasileira, por iniciativa da então deputada federal Luiza Erundina e sancionado pela presidenta Dilma Rousseff (HADDAD, 2019:220). Em meio aos protestos que apoiavam o Golpe a Dilma, ressurgiram velhas questões sobre o trabalho do educador, tais como: "chega de doutrina marxista, basta de Paulo Freire".

Assim, Freire novamente voltou aos palcos das críticas, acusado até de piorar a educação brasileira, pautados em discursos e movimentos como Escola sem Partido, Brasil Livre e Revoltados online. Para desqualificá-lo, surgiu até uma proposta legislativa para a retirada do título de patrono da educação brasileira. No entanto, diante da pressão da sociedade civil e de parlamentares favoráveis à homenagem, o pedido não foi aprovado. Haddad menciona ainda a defesa da erradicação dos conceitos freirianos especialmente após a vitória de Jair Bolsonaro, nas eleições de 2018, para a Presidência da República. Como contra-argumento, Haddad disponibiliza uma entrevista de Paulo Freire defendendo suas ideias, em que afirma que a oportunidade de ter lido Marx nunca o impediu de ter um encontro com Cristo. 
Como balanço final, impõe-se assumir que o conteúdo do livro escrito por Sergio Haddad proporciona ao leitor valioso e pormenorizado documento sobre a vida pessoal e profissional de Paulo Freire, revelando um homem de perfil inovador, crítico, ousado, original e, sobretudo, humano. A obra cumpre a difícil missão de adentrar seara tão pródiga da atuação desse educador que, além de apresentar um grande repertório de publicações, desenvolveu diversos projetos educacionais.

Enfim, o conteúdo de $\mathrm{O}$ educador: um perfil de Paulo Freire extrapola os limites da educação e resulta em uma preciosa fonte inesgotável de pesquisa para a compreensão das fragilidades políticas, históricas e sociais da humanidade. Traduz alguns dos múltiplos perfis desse grande pensador brasileiro que buscou ao longo da vida não apenas ensinar a ler as palavras, mas o mundo, criticamente.

Recebido em 06/08/2020. Aprovado em 19/08/2020.

\section{Sobre as autoras:}

\section{LUCIENE GOMES FREITAS MARINS}

Professora no curso de Licenciatura em Educação do Campo da Universidade Federal de Mato Grosso do Sul.

CARLA REGINA DE SOUZA FIGUEIREDO

Professora no curso de Licenciatura em Letras da Universidade Estadual de Mato Grosso do Sul. 